\title{
Machining Performance Optimization for Electro Discharge Machining of Inconel 625: A Case Experimental Study
}

\author{
Rahul, Chandramani Upadhyay, Saurav Datta, Bibhuti Bhusan Biswal, and Siba Sankar Mahapatra
}

\begin{abstract}
An experimental investigation on assessing machining performance during Electro-Discharge Machining (EDM) of Inconel 625 has been attempted herein. Based on 5-factor-4-level $L_{16}$ orthogonal array, experiments have been carried out by varying gap voltage, peak current, pulse-on time, duty factor and flushing pressure (each varied into four discrete levels) to examine machining performance characteristics like electrode wear ratio, radial overcut, roughness average, and surface crack density of EDMed end product obtained by utilizing different parameters settings as per design of experiment. An integrated optimization route combining satisfaction function approach and Taguchi's philosophy has been proposed for simultaneous optimization of aforementioned multiple performance indices. Predicted optimal parameters setting has been verified by confirmatory tests. In addition to that, analysis of SEM micrographs has been carried out to investigate surface irregularities for EDMed Inconel 625 end products.
\end{abstract}

Index Terms-Electro-discharge machining, inconel 625, satisfaction function approach, Taguchi's philosophy.

\section{INTRODUCTION}

Inconel alloys are Nickel-Chromium based high temperature super alloys popular for applications in aerospace, marine, and nuclear power generation, chemical, petrochemical and process industries. While machining Inconel, the significant challenges are that they have low thermal conductivity which increases thermal effects during machining; they often exhibit strong work hardening behaviour, high adhesion characteristic onto the tool face altering cutting process parameters completely. In addition, they may contain hard abrasive particles and carbides that create excessive tool wear, and hence, the surface integrity of the end products appears disappointing [1]-[4]. Compared to conventional cutting, electrical discharge machining (EDM) seems a competent alternative to machine those super alloys. It is an indeed necessity to determine the most favorable process environment (parameters setting) to optimize multiple process-performance yields, simultaneously.

Manuscript received February 16, 2016; revised July 15, 2016.

Rahul and Bibhuti Bhusan Biswal are with the Department of Industrial Design, National Institute of Technology Rourkela-769008, India (e-mail: rahulkumar589@gmail.com, bbbiswal@nitrkl.ac.in).

Chandramani Upadhyay, Saurav Datta, and Siba Sankar Mahapatra are with the Department of Mechanical Engineering, National Institute of Technology, Rourkela-769008, INDIA (e-mail: chandramani.14dec@gmail.com, sdattaju@gmail.com,ssm@nitrkl.ac.in).

\section{EXPERIMENTAL DETAILS}

Inconel 625 plates $(50 \times 50 \times 5)$ have been used as work material. The EDAX elemental spectra for revealing chemical composition of as received Inconel 625 has been depicted in Fig. 1. Graphite rod $(\phi 12)$ has been used as a tool electrode (Fig. 2). The experiments have been carried out on die sinking EDM (Make: Electronica ElektraPlusPS 50ZNC, India) setup. Commercially available grade EDM oil with specific gravity of 0.763 has been used as dielectric fluid. Polarity has been kept positive (i.e., workpiece positive). Experiments have been carried out using five controllable process parameters (gap voltage, peak current, pulse-on time, duty factor, and flushing pressure) each varied at four different levels (Table I). The design of experiment has been planned as per 5-factor-4-level $\mathrm{L}_{16}$ Orthogonal Array (OA). The machining duration for each experimental run has been kept constant (10 minutes). The machining responses viz. Electrode Wear Ratio (EWR), Radial Overcut (ROC), Roughness average $\left(\mathrm{R}_{\mathrm{a}}\right)$ and Surface Crack Density (SCD) etc. have been measured for each experimental run. The snapshot of EDMed Inconel 625 has been furnished in Fig. 3.

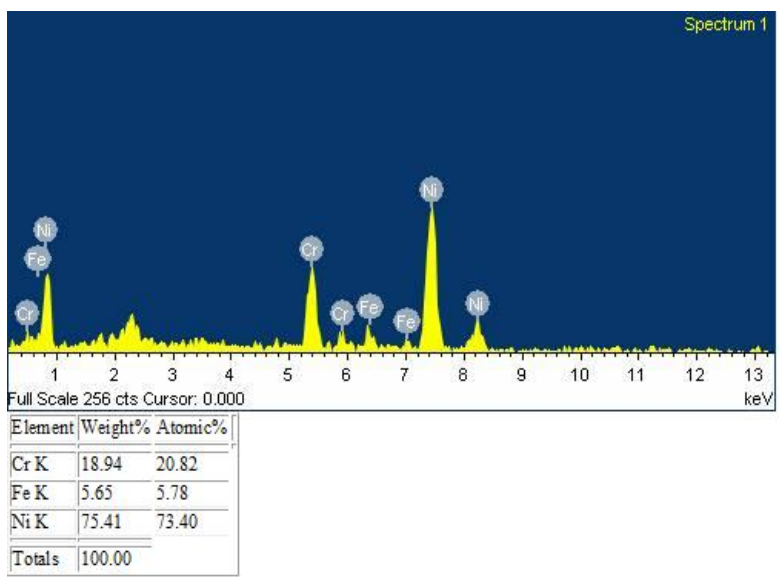

Fig. 1. Chemical composition of as received Inconel 625 (EDAX elemental spectra).

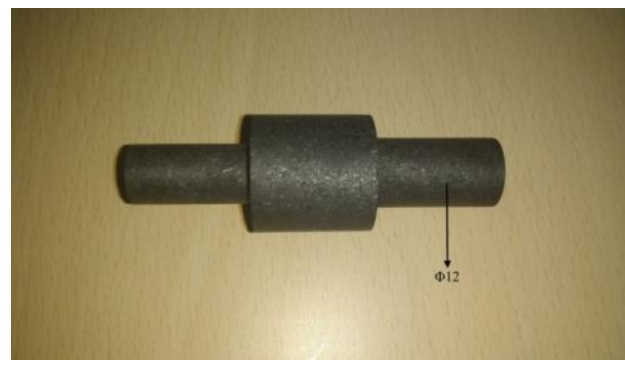

Fig. 2. Graphite electrode. 


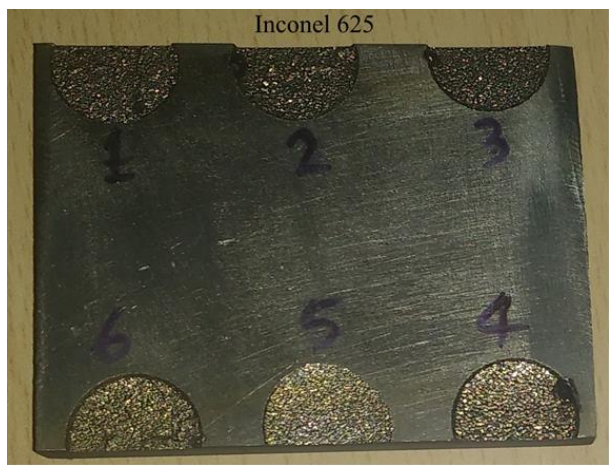

Fig. 3. EDMed Inconel 625 specimens.

TABLE I: DOMAIN OF EXPERIMENTS

\begin{tabular}{ccccccc}
\hline \hline Parameters & Unit & Notation & \multicolumn{4}{c}{ Levels of variation } \\
\hline Gap voltage $(\mathrm{V})$ & {$[\mathrm{V}]$} & $\mathrm{A}$ & 60 & 70 & 80 & 90 \\
Peak current $\left(\mathrm{I}_{\mathrm{P}}\right)$ & {$[\mathrm{A}]$} & $\mathrm{B}$ & 5 & 7 & 9 & 11 \\
Pulse-on Time & {$[\mu \mathrm{s}]$} & $\mathrm{C}$ & 200 & 300 & 400 & 500 \\
$\left(\mathrm{~T}_{\mathrm{on}}\right)$ & & & & & & \\
Duty Factor $(\tau)$ & {$[\%]$} & $\mathrm{D}$ & 70 & 75 & 80 & 85 \\
Flushing Pr. $\left(\mathrm{F}_{\mathrm{p}}\right)$ & {$[\mathrm{bar}]$} & $\mathrm{E}$ & 0.3 & 0.4 & 0.5 & 0.6 \\
\hline \hline
\end{tabular}

\section{RESULTS AND DisCUSSIONS}

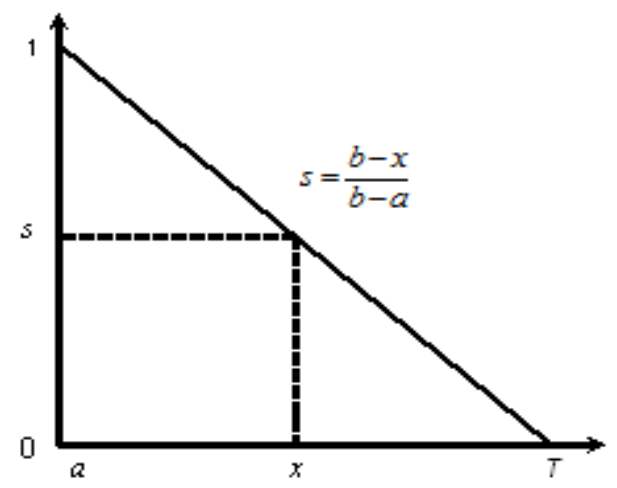

Fig. 4. Degree of satisfaction chart for a characteristic where the minimum value provides the best satisfaction (Lower-is-Better).

Experimental data (Table II) in relation to machining performance features: EWR, ROC, $R_{a}$ and SCD (in all experimental runs) have been utilized to compute satisfaction values of individual responses. In this computation, Fig. 4 has been used to compute satisfaction values of EWR, ROC, $R_{a}$ and SCD as these responses correspond to Lower-is-Better (LB) type. By exploring the concept of distance measure [5], [6], $\left(d_{T}\right)$ has been determined for each of the alternative settings; finally, $\left(d_{T}\right)$ has been optimized by Taguchi method. Taguchi method determines optimal setting of process parameters by maximizing $\mathrm{S} / \mathrm{N}$ ratio of the $\left(d_{T}\right)$. Whilst computing $\mathrm{S} / \mathrm{N}$ ratio of $\left(d_{T}\right)$, a Lower-is-Better (LB) formulation has been employed (Eq. 1).

$$
\left.\frac{S}{N}\right|_{(L B)}=-10 \log \left[\frac{1}{T} \sum_{i=1}^{T} y_{i}^{2}\right]
$$

Here $y_{i}$ represents response characteristic value on $i^{\text {th }}$ experimental run (corresponds to a particular parameters setting). Also $T$ indicates the total number of trials (experiments) at that particular parameters setting. Upon optimization, Taguchi predicted optimal setting appears as:
$\mathrm{A}_{3} \mathrm{~B}_{2} \mathrm{C}_{4} \mathrm{D}_{3} \mathrm{E}_{1}$ (Fig. 5) Predicted S/N ratio of $\left(d_{T}\right)$ at optimal setting has been determined as: $6.09197 \mathrm{~dB}$. In all cases (except run no. 10), predicted $\mathrm{S} / \mathrm{N}$ ratio at optimal setting has been found maximum as compared to the $\mathrm{S} / \mathrm{N}$ ratio values as computed for all experimental runs. The parametric setting of run no. 10 corresponds to similar $\mathrm{S} / \mathrm{N}$ value as predicted at optimal setting. This exhibits correctness of the optimization result indicating that setting 10 is the best setting.

TABLE II: EXPERIMENTAL DATA

\begin{tabular}{|c|c|c|c|c|c|c|c|c|c|}
\hline \multirow[t]{3}{*}{$\begin{array}{l}\text { Sl. } \\
\text { No } \\
\text {. }\end{array}$} & \multicolumn{5}{|c|}{$\begin{array}{l}\mathrm{L}_{16} \mathrm{OA} \text { (factors } \\
\text { are in coded } \\
\text { form) }\end{array}$} & \multicolumn{4}{|c|}{ Experimental data } \\
\hline & \multirow[t]{2}{*}{$\mathrm{A}$} & \multirow[t]{2}{*}{$\mathrm{B}$} & \multirow[t]{2}{*}{$\mathrm{C}$} & \multirow[t]{2}{*}{$\mathrm{D}$} & \multirow[t]{2}{*}{$\mathrm{E}$} & \multicolumn{4}{|c|}{ Inconel 625} \\
\hline & & & & & & $\begin{array}{c}\text { EWR } \\
{[\%]}\end{array}$ & $\begin{array}{c}\text { Radial } \\
\text { Overcut } \\
\text { (ROC) } \\
{[\mathrm{mm}]}\end{array}$ & $\begin{array}{c}\text { Roughne } \\
\text { ss } \\
\text { average } \\
\left(\mathrm{R}_{\mathrm{a}}\right) \\
{[\mu \mathrm{m}]}\end{array}$ & $\begin{array}{c}\mathrm{SCD} \\
{[\mu \mathrm{m} / \mu} \\
\left.\mathrm{m}^{2}\right]\end{array}$ \\
\hline 1 & 1 & 1 & 1 & 1 & 1 & 0.2519 & 0.263 & 7.6333 & 0.0281 \\
\hline 2 & 1 & 2 & 2 & 2 & 2 & 0.7968 & 0.416 & 8.2333 & 0.0157 \\
\hline 3 & 1 & 3 & 3 & 3 & 3 & 1.1299 & 0.478 & 9.8667 & 0.0152 \\
\hline 4 & 1 & 4 & 4 & 4 & 4 & 0.5242 & 0.562 & 10.7333 & 0.0169 \\
\hline 5 & 2 & 1 & 2 & 3 & 4 & 0.8547 & 0.191 & 4.8667 & 0.0180 \\
\hline 6 & 2 & 2 & 1 & 4 & 3 & 0.2662 & 0.427 & 8.7000 & 0.0177 \\
\hline 7 & 2 & 3 & 4 & 1 & 2 & 0.6231 & 0.663 & 7.6000 & 0.0238 \\
\hline 8 & 2 & 4 & 3 & 2 & 1 & 0.3434 & 0.635 & 8.9667 & 0.0148 \\
\hline 9 & 3 & 1 & 3 & 4 & 2 & 1.5152 & 0.119 & 6.5333 & 0.0169 \\
\hline 10 & 3 & 2 & 4 & 3 & 1 & 0.5128 & 0.203 & 7.0000 & 0.0171 \\
\hline 11 & 3 & 3 & 1 & 2 & 4 & 0.1467 & 0.382 & 9.4667 & 0.0158 \\
\hline 12 & 3 & 4 & 2 & 1 & 3 & 0.3497 & 0.392 & 10.5000 & 0.0186 \\
\hline 13 & 4 & 1 & 4 & 2 & 3 & 0.8850 & 0.123 & 4.7000 & 0.0164 \\
\hline 14 & 4 & 2 & 3 & 1 & 4 & 0.8163 & 0.241 & 7.6333 & 0.0216 \\
\hline 15 & 4 & 3 & 2 & 4 & 1 & 0.3745 & 0.332 & 9.2000 & 0.0190 \\
\hline 16 & 4 & 4 & 1 & 3 & 2 & 0.1213 & 0.257 & 11.5333 & 0.0233 \\
\hline
\end{tabular}

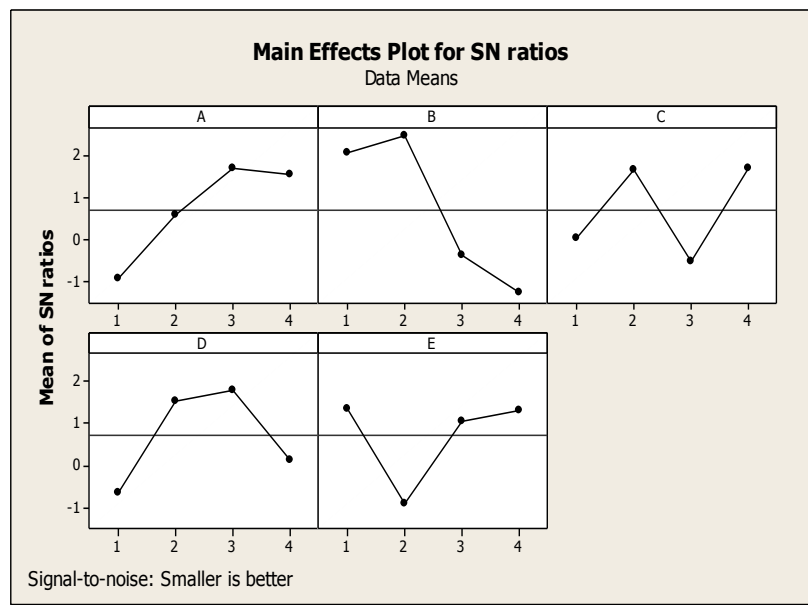

Fig. 5. S/N ratio plot: Evaluation of optimal setting (Optimization of $\left.\mathrm{d}_{\mathrm{T}}\right)$ [Optimal setting: $\mathrm{A}_{3} \mathrm{~B}_{2} \mathrm{C}_{4} \mathrm{D}_{3} \mathrm{E}_{1}$ ].

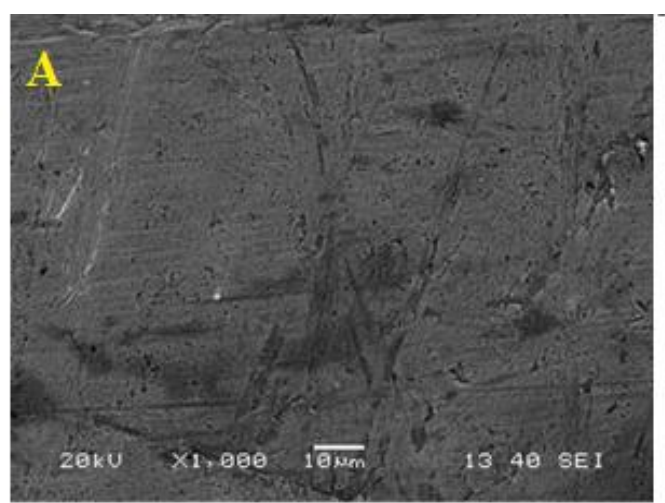

(Before machining) 


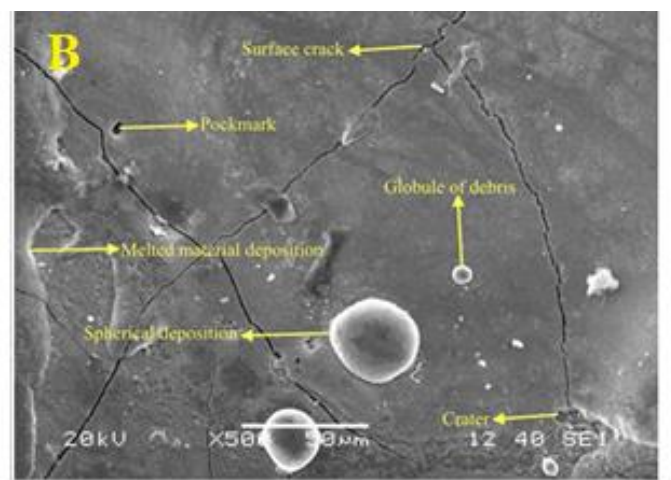

(After machining at parameters setting number 11)

Fig. 6. (A) and (B). SEM images revealing surface structure of Inconel 625 (before and after machining).

\section{ANALYSIS OF SEM MICROGRAPHS}

SEM micrographs revealing surface structure of Inconel 625 specimen (before and after machining) have been provided in Fig. 6. Observations of the EDMed surface revealed surface irregularities in terms of voids, globules of debris, an uneven fusing structure (melted metal deposition), craters and pockmarks, and surface cracks.

\section{CONCLUSION}

- The proposed satisfaction function based Taguchi's philosophy has been demonstrated herein to determine the best suitable combination of EDM parameters to improve machining performances in terms of EWR, ROC $R_{a}$, and SCD. Owing to the inability of Taguchi method to solve multi-response optimization problem, the proposed satisfaction function and distance based approach seems helpful in aggregating multiple response features into an equivalent single index (i.e. $d_{T}$ in the present case) which has been optimized finally by Taguchi method.

- With the EDM setup utilized herein and within selected parametric domain, the optimal machining environment appears: $\mathrm{OCV}=80 \mathrm{~V}, I_{p}=7 \mathrm{~A}, T_{o n}=500 \mu \mathrm{s}, \tau=80 \%$ and $F_{P}=0.3$ bar to minimize EWR, ROC, $R_{a}$, and SCD. Optimal result has also been verified by confirmatory test. It has been observed from the mean response table (mean $\mathrm{S} / \mathrm{N}$ ratio of $\left.d_{T}\right)$ that peak current $\left(I_{P}\right)$ has been appeared as the most significant parameter to influence machining performances.

- SEM images of EDMed surfaces of Inconel 625 have also been investigated. It has been concluded that by proper tuning of process parameters surface defects, irregularities, formation of cracks, etc. can be substantially reduced.

\section{REFERENCES}

[1] M. S. Hewidy, T. A. El-Taweel, and M. F. El-Safty, "Modelling the machining parameters of wire electrical discharge machining of Inconel 601 using RSM," Journal of Materials Processing Technology, vol. 169, no. 2, pp. 328-336, 2005

[2] T. R. Newton, S. N. Melkote, T. R. Watkins, R. M. Trejo, and L. Reister, "Investigation of the effect of process parameters on the formation and characteristics of recast layer in wire-EDM of Inconel 718," Materials Science and Engineering: A, vol. 513, pp. 208-215, 2009.
[3] M. Y. Lin, C. C. Tsao, C. Y. Hsu, A. H. Chiou, P. C. Huang, and Y. C. Lin, "Optimization of micro milling electrical discharge machining of Inconel 718 by Grey-Taguchi method," Transactions of Nonferrous Metals Society of China, vol. 23, no. 3, pp. 661-666, 2013.

[4] M. Ay, U. Çaydaş, and A. Hasçalık, "Optimization of micro-EDM drilling of inconel 718 superalloy," The International Journal of Advanced Manufacturing Technology, vol. 66, no. 5-8, pp. 1015-1023, 2013.

[5] M. S. Cherif, H. Chabchoub, and B. Aouni, "Quality control system design through the goal programming model and the satisfaction functions," European Journal of Operational Research, vol. 186, no. 3, pp. 1084-1098, 2008.

[6] A. Kentli and A.K. Kar, "A satisfaction function and distance measure based multi-criteria robot selection procedure," International Journal of Production Research, vol. 49, no. 19, pp. 5821-5832, 2011.

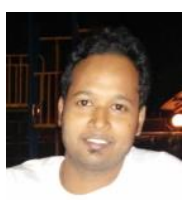

Rahul is a Ph.D. Research Scholar in the Department of Industrial Design, National Institute of Technology Rourkela, India. He completed has B. Tech. from JSS Academy of Technical Education, Noida in the year 2011, did his M. Tech. in Department of Mechanical Engineering (Specialization in Welding and Fabrication) from Sant Longowal Institute of Engineering and Technology, Sangrur, Punjab in 2013. His area of interest includes modeling and simulation manufacturing processes, multi-objective optimization etc.

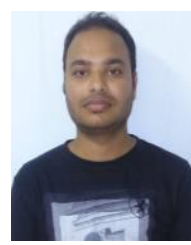

Chandramani Upadhyay is a M. Tech. scholar in the Department of Mechanical Engineering, National Institute of Technology, Rourkela, India. He has completed his B. Tech. from I.T.M. GIDA Gorakhpur in the year 2010. His area of interest includes manufacturing science, modelling and optimization of production systems.

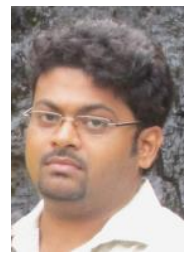

Saurav Datta is presently serving as Assistant Professor in the Department of Mechanical Engineering, National Institute of Technology, Rourkela, India. His current area of research includes weld quality optimization, modeling and simulation of production processes, and multi-criteria decision-making. He has published a number of journal papers of national/ international repute and presented a number of papers in various conferences/ symposia in India and abroad. He is presently guiding a number of research scholars for M. Tech. / Ph. D.

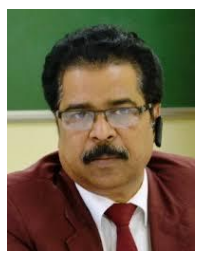

Bibhuti Bhusan Biswal is a Professor in the Department of Industrial Design, National Institute of Technology, Rourkela, India. He is presently acting as Dean (faculty Welfare) of this institute. He has vast experience in teaching, research and institute administration (as Prof. In-Charge, Training and Placement). His current area of research includes robotics, neural networks, and non-traditional optimization and simulation

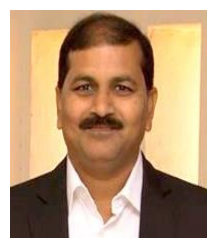

Siba Sankar Mahapatra is a Professor in the Department of Mechanical Engineering, National Institute of Technology, Rourkela, India. He has more than 20 years of experience in teaching and research His current area of research includes multi-criteria decision-making, quality engineering, assembly line balancing, group technology, neural networks, and non-traditional optimization and simulation. He has published more than 40 journal papers. He has written few books related to his research work. He is currently dealing with few sponsored projects. 